\title{
Photo-catalytic Removal of Methyl Orange Dye by Polyaniline Modified ZnO using Visible Radiation
}

\author{
Melaku Wondwossen ${ }^{1 *}$, Yadav $O \mathrm{P}^{2}$ and Kebede Tesfahun ${ }^{3}$ \\ ${ }^{1}$ Department of Chemistry, Collage of Natural and Computational Sciences, Mizan-Tepi University, \\ Tepi Campus, Post Box No: 121,Tepi, Ethiopia \\ ${ }^{2,3}$ Department of Chemistry, Natural and Computational Sciences, Haramaya University, \\ Post Box No: 203, Dire Dawa, Ethiopia.
}

\begin{abstract}
Polyaniline modified zinc oxide (PANI/ZnO) nanocomposite was synthesized by in-situ polymerization process. The as-synthesized nano-ZnO, PANI and PANI/ZnO nanocomposite were characterized by X-ray diffraction (XRD), FT-IR, and UV-Vis spectroscopy. The UV-visible spectroscopy studies showed that the absorption peak for PANI/ZnO nanocomposite has a red shift toward visible wavelengths compared with the $\mathrm{ZnO}$ nanoparticles and PANI. Photocatalytic efficiency of PANI/ZnO nanocomposite was investigated for the degradation of methyl orange $(\mathrm{MeO})$ dye as a model organic compound under Visible light irradiation. The photocatalytic activities of $\mathrm{ZnO}$, PANI and PANI/ZnO nanocomposite were studied. The results showed that ZnO/PANI nanocomposite had greater photocatalytic activity than $\mathrm{ZnO}$ nanoparticles and PANI under visible light irradiation. According to these results, application of PANI as a shell on the surface of $\mathrm{ZnO}$ nanoparticles causes the enhanced photocatalytic activity of the PANI/ZnO nanocomposite. Influence of some operational parameters such as: amount of photocatalyst, $\mathrm{pH}$ of solution, and $\mathrm{MeO}$ dye initial concentration on the photodegradation reaction rate was investigated. The optimum values of $\mathrm{pH}$ and catalyst dose found to be 6 and $1.50 \mathrm{gmL}^{-1}$ respectively. It was demonstrated that the photocatalytic degradation of $\mathrm{MeO}$ follows pseudo first-order kinetics. The PANI/ZnO nanocomposite photocatalysts have good photocatalytic stability and can be reused three times with only gradual loss of activity. Thus, the PANI/ZnO nanocomposites are efficient photocatalytic materials for degrading contaminated colored wastewater for reuse in textile industries under mild conditions.
\end{abstract}

Copyright@2014 STAR Journal. All Rights Reserved.

Article Information

Article History:

Received : 20-03-2014

Revised : 29-05-2014

Accepted : 11-06-2014

Keywords:

PANI/ZnO Nanocomposite

Methyl orange

Visible light

photo-catalysis

Degradation rate constant

${ }^{*}$ Corresponding Author:

Melaku Wondwossen

E-mail:

wondosenmelaku@gmail.com

\section{INTRODUCTION}

Industries produce a large amount of organic contaminants including dyes which are toxic and non biodegradable. The presence of these contaminants has caused severe environmental pollution problems by releasing toxic and potential carcinogenic substances into the aqueous phase (Kansal et al., 2007 and Rashcd, 2007). Contaminants which widely encountered in water are: dyes, chlorinated hydrocarbons, phenol derivative, insecticides, pesticides and pharmaceutical formulations (Doong et al., 2001 and Hilal et al., 2007).

Various chemical and physical processes such as adsorption, air stirring, flocculation, reverse osmosis and ultra filtration can be used for water purification. But, these techniques are non-destructive and a new type of pollution will arise which needs further treatment (Neppolian et al., 2002). Recently, photo catalytic reactions induced by illumination of semiconductors in suspension has been shown to be one of the most promising processes for the wastewater treatment due to its advantages over the traditional techniques, since they provide an interface with an aqueous medium and induce an advanced oxidation process (AOPs), no formation of polycyclic products, oxidation of pollutants in the ppb range (Dai et al., 2007). AOPs are based on generation of reactive species such as hydroxyl radicals obtained by the reaction of holes with surface hydroxyl or water and their attachment to organic compound that oxidize a broad range of pollutants efficiently. AOPs include photocatalysis systems such as combination of semiconductors with light and semiconductor with oxidant (Doong et al., 2001 and Kansal et al., 2007). Many different semiconductor materials, such as $\mathrm{TiO}_{2}, \mathrm{ZnO}, \mathrm{ZrO}_{2}, \mathrm{SrO}_{2}$, $\mathrm{Fe}_{2} \mathrm{O}_{3}, \mathrm{CdS}, \mathrm{ZnS}$ have been used to photo-degrade different pollutants (Neppolian et al., 2002). Among these, $\mathrm{TiO}_{2}$ and $\mathrm{ZnO}$ are known to be the best photo-catalysts for the degradation of several environmental contaminants (Doong et al., 2001 and Neppolian et al., 2002).

$\mathrm{ZnO}$ has been used to photo-degrade water contaminants in the UV region, but to a much lesser extent than $\mathrm{TiO}_{2}$. $\mathrm{ZnO}$ has comparable band gap (3.34 
Melaku Wondwossen et al.,

eV) to that of $\mathrm{TiO}_{2}(3.2 \mathrm{eV})$. However, the greatest advantage of $\mathrm{ZnO}$ is that it absorbs large fraction of solar UV light than $\mathrm{TiO}_{2}$ does (Kansal et al., 2007). $\mathrm{TiO}_{2}$ can utilize only about $3.0 \%$ of the solar light reaching the earth surface for decomposition of organic compounds (Chen et al., 2005). The efficient use of sun light became an appealing challenge for developing photoccatalysts (Hilal et al., 2007 and Bessekhouad et al., 2004). One approach to solve the above problems is to sensitize $\mathrm{TiO}_{2}$ and $\mathrm{ZnO}$ by using narrow band gap semi-conductors with higher conduction band. Some investigations indicated that, the combination of a narrow band gap semiconductor with another with broad band gap results in a better separation of the charge carrier and a quicker transfer of photogenerated electrons in comparison with the single semiconductor material (Georgieva et al., 2007). For example, CdS with band gap energy of $2.41 \mathrm{eV}$ is considered to be one of the many sensitizers used for large band-gap semiconductor (Chen and Jie, 2007). This is due to the ideal position of its conduction and valence band edges. CdS alone however, may show lower photocatalytic activity because of rapid electron hole pair recombination rates. Studies have proven that with the appropriate particle interaction, $\mathrm{CdS} / \mathrm{ZnO}$ nanocomposites can efficiently decompose organic compounds such as phenol, methyl orange and methylene blue under visible irradiation.

Another approach, many researches focused on increasing degradation rate of pollutants by combining inorganic materials with conductive polymers to realize synergetic and complementary behaviors between the polymer and inorganic materials (Sharma et al., 2009). Many conducting polymers are known as good hole conducting materials (Shaheen et al., 2001). These conductive polymers act as a stabilizer or surface capping agents when combined with metals or semiconductor nanoparticles (Mbhele et al., 2003, Karim et al., 2006 and Khanna et al., 2004). Conducting polyaniline (PANI) is one of the promising studied polymer, due to its high conductivity, simple synthesis procedure, good environmental stability (Gustafsson et al., 1992). There are several reports focused on increasing ultraviolet emission and photocatalytic activity of $\mathrm{ZnO}$ nanostructures combined with polyaniline conductive polymer (Ameen et al., 2011 and Chang et al., 2007).

In addition, $\mathrm{ZnO}$ has been frequently considered as an alternative to $\mathrm{TiO}_{2}$ for photocatalytic applications, since it shows similar activity in certain conditions. However, it suffers from anodic photocorrosion, differently to $\mathrm{TiO}_{2}$, and $\mathrm{ZnO}$ is soluble in strong acids and alkalis, which limits the $\mathrm{pH}$ range in which it can be used. The photocatalytic activity of semiconductor depends upon the crystallinity, surface area and particle morphology. Among these factors, crystallinity and surface area which depend on the method of preparation are regarded as important factors for determining photocatalysis (Parida et al., 2006). Inorganic nanoparticles are also very easy to agglomerate in media. To prevent agglomeration of nanoparticles in mediums, their combination with polymers is usually accomplished by surface modification. It can significantly enhance the stability of nanoparticles dispersing in polymer solvents by increasing the affinity of the surface for organic substances (Kim et al., 2005). In the present work, the efficiency of the photocatalytic destruction of methyl orange using visible light and polyaniline modified $\mathrm{ZnO}$ nanocomposite was studied. Specifically, the effect
Sci. Technol. Arts Res. J., April-June 2014, 3(2): 93-102

of irradiation time, concentration of $\mathrm{PANI} / \mathrm{ZnO}$ photocatalyst and $\mathrm{MeO}$, and $\mathrm{pH}$ of the solution were examined.

\section{MATERIALS AND METHODS \\ Chemicals}

In present study, zinc chloride (assay $\geq 98 \%$ ), aniline ( assay $\geq 99 \%$ ), ammoniumperoxydisulfate (APS) (assay $\geq$ $98 \%$ ), methyl orange, sodium hydroxide (assay 99\%), hydrochloric acid (assay $\geq 37 \%$ ) and 2-propanol (assay $\geq 99.8 \%$ ). All chemicals were analytical grade. Double distilled water was used for preparation of various solutions.

\section{Synthesis of Photocatalyst (ZnO Nanoparticles)}

$\mathrm{ZnO}$ nanoparticle synthesis method was adapted from (Kathirvelu et al., 2009). $5.5 \mathrm{gm}$ of $\mathrm{ZnCl}_{2}$ was dissolved in $200 \mathrm{ml}$ of water at $90^{\circ} \mathrm{C}$ in a beaker and $16 \mathrm{ml}$ of $5 \mathrm{M}$ $\mathrm{NaOH}$ aqueous solution was added dropwise to the $\mathrm{ZnCl}_{2}$ solution with a gentle stirring over a period of 10 minutes. The particles were separated from the supernatant by sedimentation. The supernatant solution was discarded and the solid residue was washed five times with distilled water to remove $\mathrm{NaCl}$. The particles were peptized with 2propanol for 10 minutes at room temperature. Then the particles were collected by centrifugation at $6,000 \mathrm{rpm}$ for 15 minutes and then washed three times with distilled water. Finally, the product was thermally treated at $250^{\circ} \mathrm{C}$ for 5 hours to form $\mathrm{ZnO}$ powder.

\section{Synthesis of Photocatalyst (Polyaniline Modified ZnO (PANI/ZnO) Composite)}

A typical oxidative polymerization method was adopted for polymerization of aniline in the presence of $\mathrm{ZnO}$ nanoparticles (Olad and Nosrati, 2011). $0.9313 \mathrm{~g}$ of $\mathrm{ZnO}$ powder was added into $20 \mathrm{~mL}$ aqueous solution of 0.01 mol aniline monomer and 0.01 mol hydrochloric acid. 0.01 mol APS was dissolved in a $15 \mathrm{ml}$ distilled water and added dropwise to the mixture of $\mathrm{ZnO}$ and aniline with stirring in an ice bath. Polymerization proceeded for 5.5 hours. The composite of PANI modified $\mathrm{ZnO}$ was obtained as precipitate. The precipitate was isolated by filtration, washed with distilled water and ethanol several times, and dried at $50^{\circ} \mathrm{C}$. Pure PANI was also synthesized, by using an identical method but without using $\mathrm{ZnO}$.

\section{Characterization of Synthesized Photocatalysts}

The products were characterized by X-ray diffraction (XRD) on West Germany X-ray diffractometer (XRD) equipped with a $\mathrm{Cu}$ target for generating a $\mathrm{Cu} \mathrm{Ka}$ radiation (wavelength $1.5406 \mathrm{~A}^{\circ}$ ) as the $\mathrm{X}$-ray source. The measurements were made at room temperature and the accelerating voltage and the applied current were $40 \mathrm{kV}$, $30 \mathrm{~mA}$ respectively. The instrument was operated under step scan type with step time and degree $(2 \theta)$ of $1 \mathrm{~s}$ and $0.020^{\circ}$, respectively, ove $4^{\circ}$ to $64^{\circ}$. The UV-visible spectra of photocatalysts were measured using Perkin Elmer sectrophotometer ( model; SANYO SP65) to evaluate their photoactivation wavelengths. FTIR spectra with $\mathrm{KBr}$ pellets were recorded in the range 4000 to 400 $\mathrm{cm}^{-1}$ to infer the interaction between $\mathrm{ZnO}$ and molecular chains of PANI in the PANI/ ZnO composite.

\section{Determination of Point of Zero Charge (PZC)}

Point of zero charge (pzc) of PANI/ZnO composite was determined using the method described by Rao et al., (2011). The adsorbent $(100 \mathrm{mg})$ suspension was prepared in $50 \mathrm{ml}$ solution of $10^{-3} \mathrm{M} \mathrm{NaNO}_{3}$ and adjusted 
Melaku Wondwossen et al.,

to various $\mathrm{pH}$ values using dilute $\mathrm{NaOH}$ and $\mathrm{HNO}_{3}$ solutions. Allowing 60 min for equilibration, the initial $\mathrm{pH}$ value was measured. Then $1.0 \mathrm{~g}$ of $\mathrm{NaNO}_{3}$ is added to each aliquot to bring final electrolyte concentration to 0.45 M. Final $\mathrm{pH}$ was measured after 60 minutes agitation. A plot of $\mathrm{pH}_{\text {final-initial }}$ versus $\mathrm{pH}_{\text {final }}$ was drawn.

\section{MeO Degradation Studies}

Photocatalytic degradation of methyl orange (MeO) was carried out using a reactor (figure 1). Photocatalytic degradation experiments were carried out at room temperature $\left(25^{\circ} \mathrm{C}\right)$ at night to avoid sunlight penetration. $100 \mathrm{~mL}$ of dye solution $10 \mathrm{mgL}^{-1}$ was mixed with $150 \mathrm{mg}$ of PANI/ZnO composite. The suspension was constantly stirred for $30 \mathrm{~min}$ in dark before irradiation to reach absorption equilibrium of $\mathrm{PANI} / \mathrm{ZnO}$ with dye solution. During irradiation, the reaction mixture was maintained under magnetic stirring to achieve a homogeneous suspension, to promote the adsorption of dye on the surface of the photocatalyst (Xu et al., 1998). At each 20 minute interval, $10 \mathrm{~mL}$ dye solution was collected and centrifuged at $5000 \mathrm{rpm}$ for $10 \mathrm{~min}$ and filtered. Dye concentration was determined using UV/Visible spectrophotometer at the $\lambda_{\max }$ of $\mathrm{MeO}$ dye $(460 \mathrm{~nm})$. The photodegradation efficiency (\% degradation) was calculated using Eq.4.

$\%$ Degradation $=\frac{A_{0}-A_{t}}{A_{0}} \times 10=\left(1-\frac{A_{t}}{A_{0}}\right) \times 100$

Where $A_{0}$ is absorbance of $\mathrm{MeO}$ dye in solution at the initial stage, $A$ is the absorbance at time $(t)$.

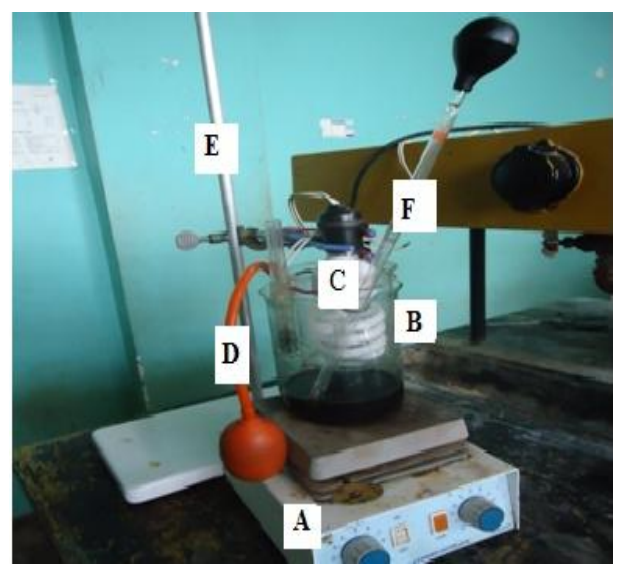

(A). Hot plate; (B). Beaker (used as reactor tube) containing the reactants and stirrer;(C). Radiation source (Tungsten lamp, 40W) (D). Purging pump to inlet air to the solution; (E). Stand to hold the lamp and $(F)$. Sample collecting pipette

Figure 1: Photocatalytic reactor.

Kinetic Studies of Photocatalytic Degradation of MeO

The kinetics of the photolytic degradations of methyl orange solutions was investigated using initial concentrations of dye in the range $10-40 \mathrm{mgL}^{-1}$, in the same operating conditions. The graph was plotted between $\ln _{0} / C_{t}$ as a function of time (t). Where, $C_{0}$ is the initial concentrations of dye and $C_{t}$ is concentration of dyes at time t. From the slope of the plot, the rate of the photocatalytic degradation of $\mathrm{MeO}$ was determined.

\section{RESULTS AND DISCUSSION}

\section{X-ray Diffraction (XRD) Analysis}

XRD patterns of PANI, PANI/ZnO and $\mathrm{ZnO}$ are shown in figure 2 . In the XRD pattern of $\mathrm{ZnO}$, the observed
Sci. Technol. Arts Res. J., April-June 2014, 3(2): 93-102

peaks at $2 \theta=32^{\circ}, 34.5^{\circ}, 36.4^{\circ}, 47.6^{\circ}, 56.5^{\circ}$, and $63^{\circ}$ correspond to planes (100),(002), (101),(102),(110) and (103), respectively, suggesting hexagonal zincite crystal structure for ZnO (Kathirrvelu et al., 2009). The broadened and intense XRD peaks indicate the formation of nanosize $\mathrm{ZnO}$ particles. Absence of extra peaks in the $\mathrm{XRD}$ indicates that there are no impurities present in the sample. The average particle size of $\mathrm{ZnO}$, considering the most intense peak of (101) is $33.87 \mathrm{~nm}$ obtained using Debye- Scherrer formula (Zheng and Wu, 2009): D $=k \lambda / \beta \operatorname{Cos} \theta$ Where $D$ is the crystallite size in $n m, K$ is the shape factor constant and taken as $0.94, \beta$ is the full width at half maximum (FWHM) in radians, $\lambda$ is the wavelength $(0.15406 \mathrm{~nm})$ of the $\mathrm{X}$-ray for $\mathrm{Cu}$ target $\mathrm{K}_{\alpha}$ radiation and $\theta$ is diffraction angle. The XRD pattern of PANI in figure 3 , two weak peaks are observed at $2 \theta=20^{\circ}$ and $2 \theta=25^{\circ}$. The peak at $2 \theta=20^{\circ}$ represents the characteristic distance between the ring planes of benzene rings in adjacent chains or the close contact inter-chain distance (Pouget et al., 1995). The peak centered at $2 \theta=25^{\circ}$ may be assigned to the scattering from PANI chains at interplanar spacing (Feng et al., 2000 and Min et al., 2007) and very low intensity of the observed peak indicates that the PANI has amorphous structure with low crystallinity. The XRD pattern of the PANI/ZnO nanocomposite (in figure 4) include the characteristic peaks of both PANI and $\mathrm{ZnO}$, which confirms the formation of nanocomposite with lower crystallinity.

\section{FT-IR Analysis}

FTIR spectrum is the feature of a particular compound that gives the information about its functional groups, molecular geometry and inter/intramolecular interactions. Figure 5 shows the FTIR spectra of $\mathrm{ZnO}$ nanoparticles. The absorption peak near $486 \mathrm{~cm}^{-1}$ is due to stretching vibrations of $\mathrm{Zn}-\mathrm{O}$ bonds. The peaks at $3435 \mathrm{~cm}^{-1}$ and $2920 \mathrm{~cm}^{-1}$ indicate the presence of $\mathrm{OH}$ and $\mathrm{C}=\mathrm{O}$ residues respectively, probably due to atmospheric moisture and $\mathrm{CO}_{2}$ respectively (Silva and Zaniquelli, 2002). Figure 6(a) shows the FTIR spectra of pure PANI. The caracterstics peaks are $1575 \mathrm{~cm}^{-1}$ due to $\mathrm{C}=\mathrm{C}$ stretching mode of the quinoid rings, $1497 \mathrm{~cm}^{-1}$ due to $\mathrm{C}=\mathrm{C}$ stretching mode of benzenoid rings, $1298 \mathrm{~cm}^{-1}$ due to $\mathrm{C}-\mathrm{N}$ stretching mode and $1151 \mathrm{~cm}^{-1}$ due to $\mathrm{N}=\mathrm{Q}=\mathrm{N}$, where $\mathrm{Q}$ represents the quionoid ring (Silva and Zaniquelli, 2002). The presence of the benzenoid and quinoid units is evidence of the emeraldine form of PANI. The FTIR spectrum of the $\mathrm{PANI} / \mathrm{ZnO}$ nanocomposite (Figure $6 \mathrm{~b}$ ) is the replica of characteristic peaks of PANI. However, the corresponding peaks are shifted to the lower wave numbers, besides their intensities are changed after the $\mathrm{ZnO}$ nanoparticles addition. The peaks of the PANI around $1575 \mathrm{~cm}^{-1}, 1497$ $\mathrm{cm}^{-1}, 1298 \mathrm{~cm}^{-1}$ and $1151 \mathrm{~cm}^{-1}$ are shifted to $1567 \mathrm{~cm}^{-1}$, $1482 \mathrm{~cm}^{-1}, 1289 \mathrm{~cm}^{-1}$ and $1132 \mathrm{~cm}^{-1}$ respectively. These shifts of characteristic peaks of the PANI may be the result of the interactions between the PANI chains and $\mathrm{ZnO}$ nanoparticles which affect the electron densities and bond energies of the PANI (Somani et al., 1999 and Niu et al., 2003). The shifting to the lower wave numbers shows the increasing the electron density of PANI chains or due to the action of hydrogen bonding between the hydroxyl groups on the surface of $\mathrm{ZnO}$ nanoparticles and the amine groups in the PANI molecular chains (He, 2005). Similar observations of shifting of absorption peaks of $\mathrm{PANI} / \mathrm{ZnO}$ towards lower wavenumber were also reported earlier (He, 2004). 


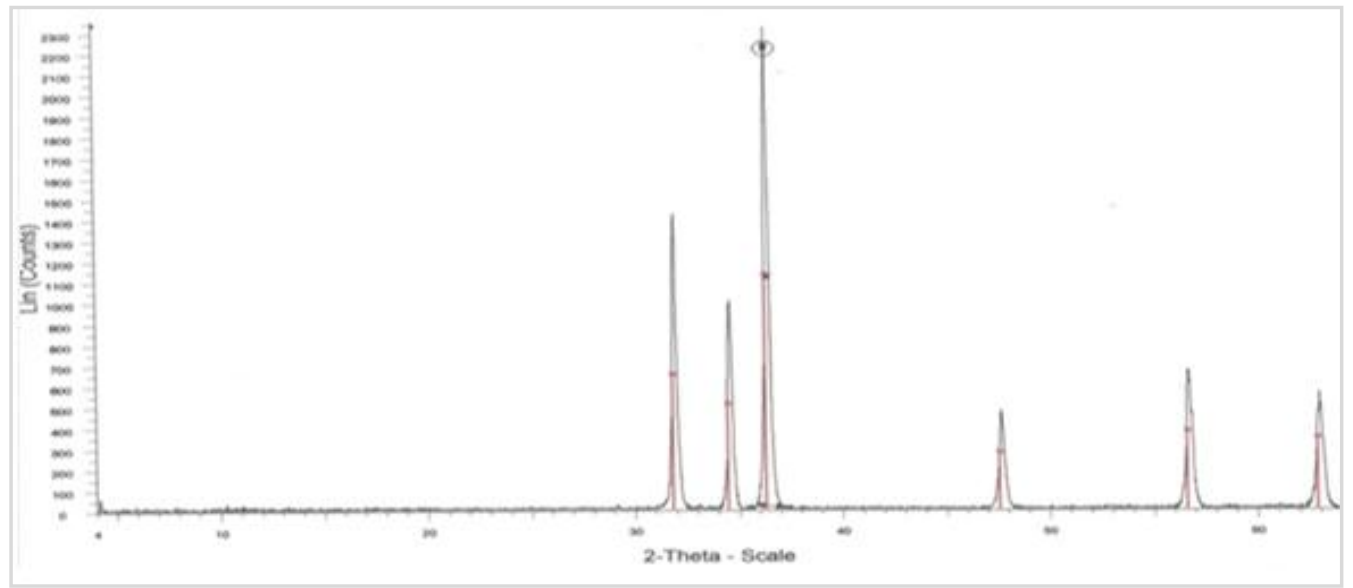

Figure 2: $\mathrm{XRD}$ pattern of $\mathrm{ZnO}$ nanoparticles

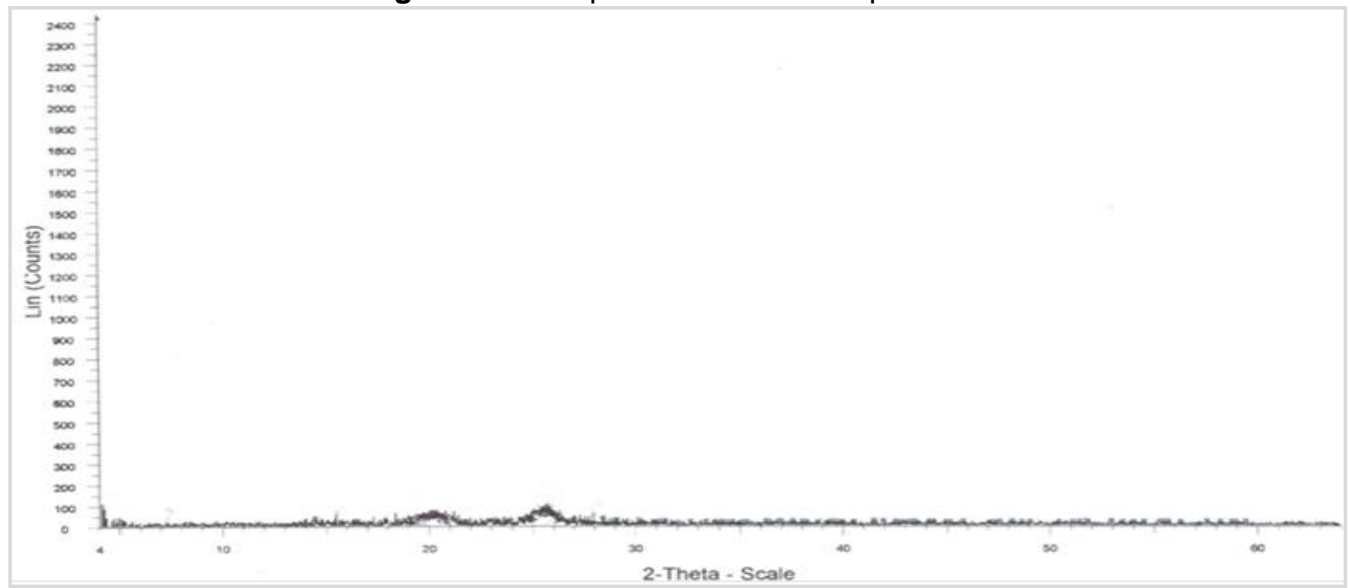

Figure 3: XRD pattern of PANI

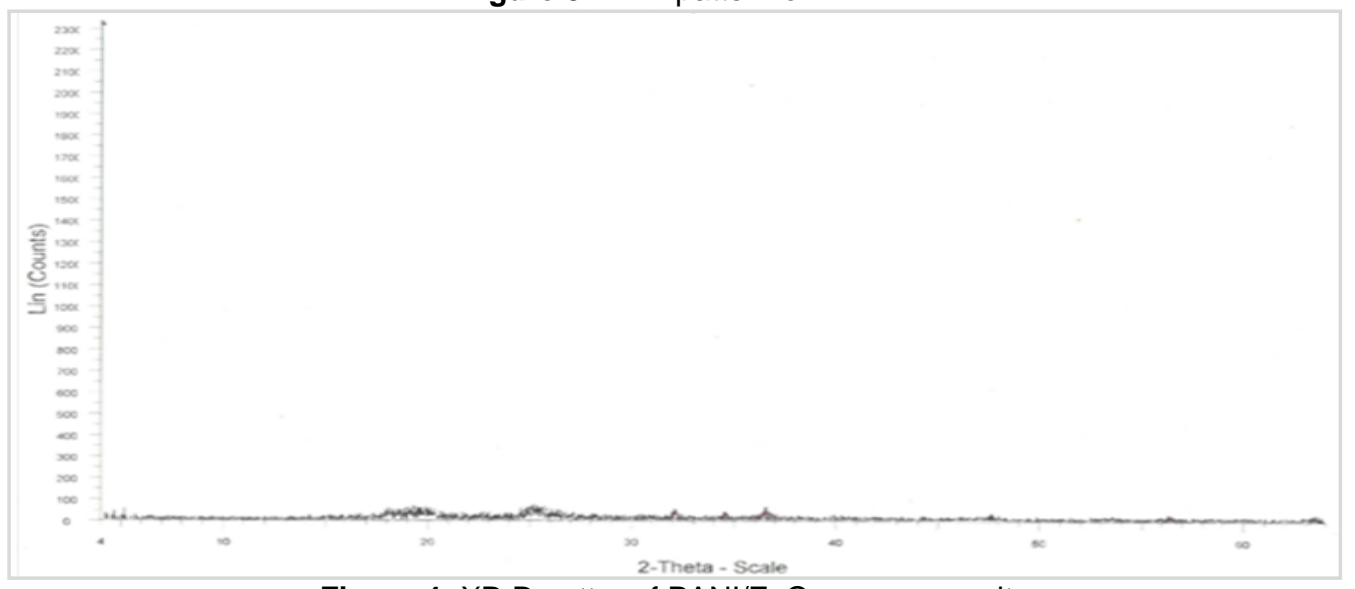

Figure 4: XR D patter of PANI/ZnO nanocomposite

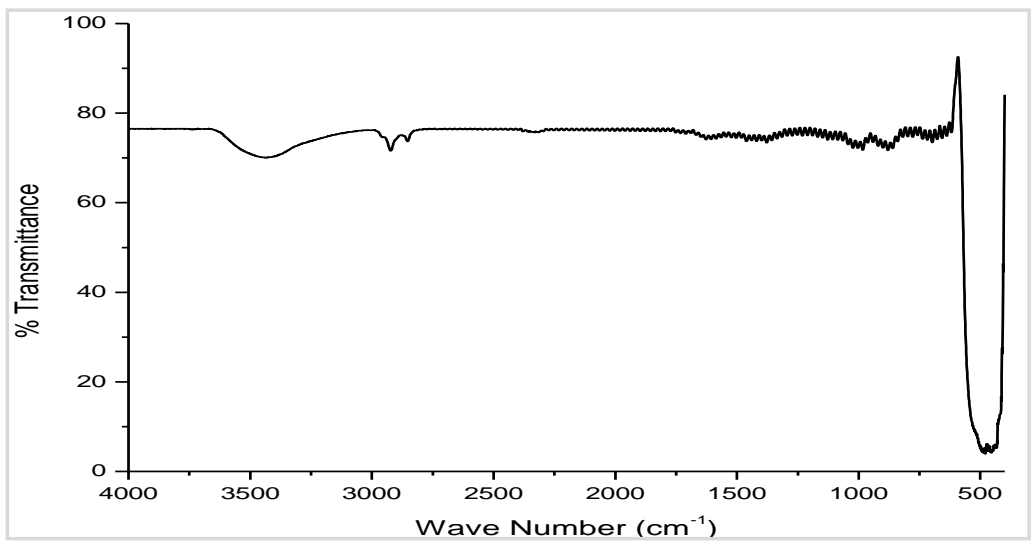

Figure 5: FTIR spectrum of $\mathrm{ZnO}$ nanoparticle 


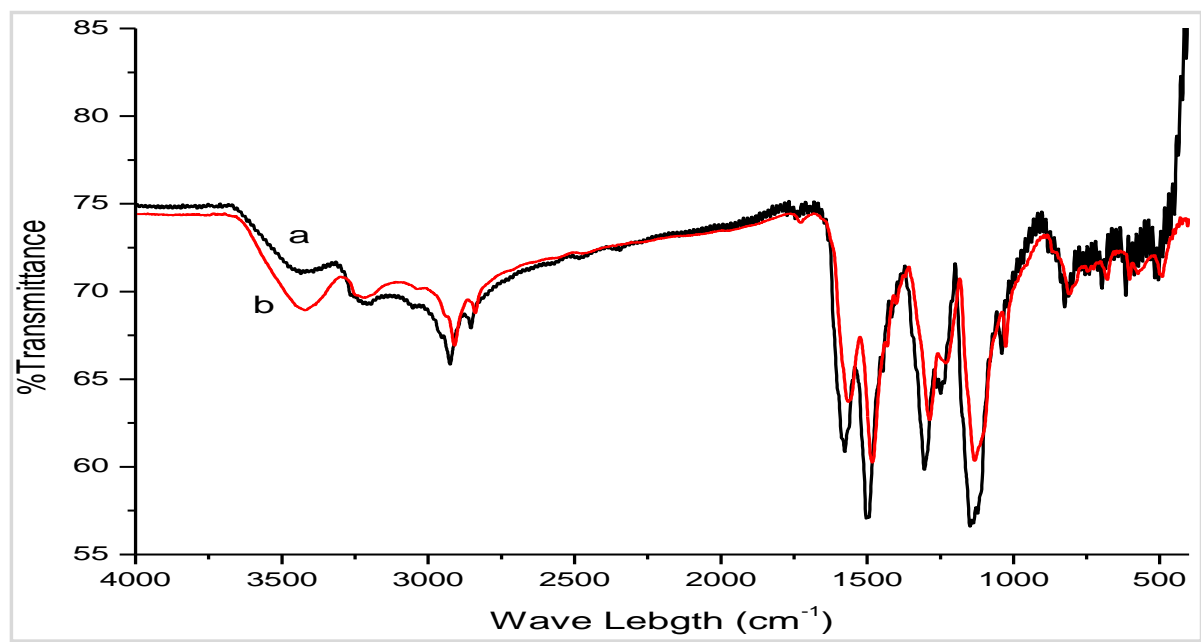

Figure 6: FTIR Spectra of a) the PANI polymer and b) PANI/ZnO nanocomposite

\section{UV-Vis Absorption Spectra}

To investigate the effect of combining $\mathrm{ZnO}$ nanoparticles with PANI on the spectroscopic absorption of $\mathrm{ZnO}$ nanoparticles, the UV-visible absorption spectra of all components were recorded and analyzed. Figure 7 shows the UV-visible spectra of $\mathrm{ZnO}$ nanoparticles (a), PANI (b) and PANI/ZnO nanocomposite (c). The absorption spectrum of the $\mathrm{ZnO}$ nanoparticles (Figure 7a) presents a sharp absorption peak around $379 \mathrm{~nm}$ which is the characteristic single peak of hexagonal $\mathrm{ZnO}$ nanoparticles. PANI shows absorption both in UV range as well as in the visible region. As reported previously by some researchers doped forms of PANI shows usually three characteristic absorption bands at 320-360, 400-450 and 740-960 nm (Wang et al., 2010). The first absorption band arises from $\pi-\pi^{*}$ electron transition within benzenoid segments (Sedenkova et al., 2008). The second and third absorption bands are related to doping level and formation of polarons (quinoid segments), respectively. Similarly, the PANI has absorption band around $447 \mathrm{~nm}$ as shown in figure $7 \mathrm{~b}$. In the literature, the absorption peaks of PANI between $700-800 \mathrm{~nm}$ was related with the presence of acidic solvents used as medium during polymerization of aniline (Xu et al., 2007). The UV-visible spectrum of the PANI/ZnO nanocomposite (figure $7 \mathrm{c}$ ) has an absorption peak at
$471 \mathrm{~nm}$, which is red shifted compared with the absorption peaks of pristine PANI (454 nm) and of $\mathrm{ZnO}$ nanoparticles $(379 \mathrm{~nm})$. This may be because of interactions between $\mathrm{PANI}$ chains and $\mathrm{ZnO}$ nanoparticles which cause easy charge transfer from PANI to $\mathrm{ZnO}$ via hydrogen bonding. Compared with neat $\mathrm{ZnO}$, the absorption of PANI modified $\mathrm{ZnO}$ sample increases over the whole range of visible light whereas decreases in the UV range (Olad and Nosrati, 2011). According to these results, the synthesized PANI/ZnO nanocomposite that shows shift of absorption peak in the visible region, it was photoactivated by visible light irradiation compared to $\mathrm{ZnO}$ photocatalyst nanoparticles which are photoactivated under harmful UV light irradiation. This may be the main advantage of the PANI/ZnO nanocomposite prepared in this study, which has a special structure which is only photoactivated under visible light irradiation.

The band gap energy $\left(E_{g}\right)$ of photocatalyst was obtained using the equation: $E_{g}=\frac{1240}{\lambda} \mathrm{eV}$, where $E_{g}$ is the band gap energy $(\mathrm{eV}), \lambda$ the absorption adge wavelength (nm) (El-Kemary et al., 2010). The band gap energy of $\mathrm{ZnO}$ and PANI/ZnO composite are 3.27 and $2.73 \mathrm{eV}$, respectively.

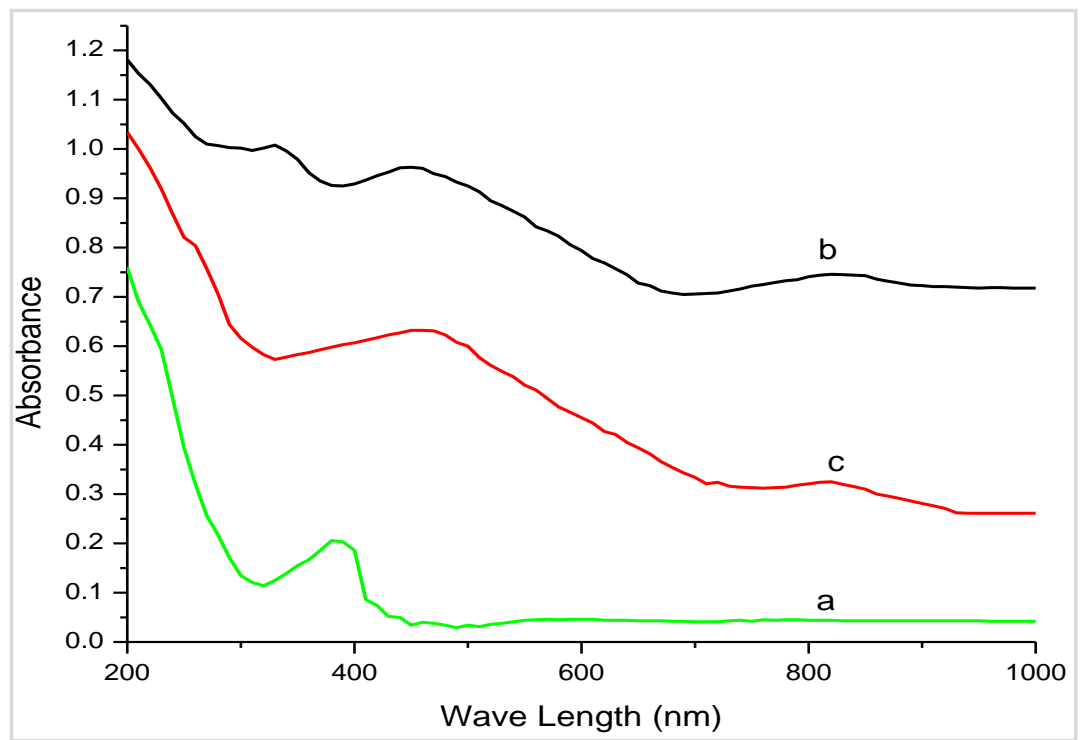

Figure 7: UV-visible spectra of ZnO nanoparticles (a), pristine PANI (b), and PANI/ZnO nanocomposite (c) 
Melaku Wondwossen et al.,

\section{Point of Zero Charge (pzc) of PANI/ZnO} Nanocomposite

The plot of $\mathrm{pH}_{\mathrm{f}}$ versus $\mathrm{pH}_{\mathrm{f}-\mathrm{i}}$ is shown in figure 8. The $\mathrm{pH}_{\mathrm{zpc}}$ values for adsorbent/ photocatalyst PANI/ZnO nanocomposte is 8.17 . This means that the $P A N I / Z n O$ nanocomposite has acidic nature below 8.17 , basic nature above 8.17 and neutral at $\mathrm{pH}=8.17$.

\section{Methyle Orange Degradation Studies \\ Comparision of Photocatalysts}

Photocatalytic activity of as-synthesized $\mathrm{ZnO}$ nanoparticles, pristine PANI, and PANI/ZnO nanocomposite under visible light irradiation for degradation of $\mathrm{MeO}$ dye molecules was evaluated and compared. Figure 9 shows the percentage degradation of $\mathrm{MeO}$ dye in solutions with the same dye initial concentration of $10 \mathrm{mg} \mathrm{L}^{-1}$ with the same amount $(1.50 \mathrm{gm}$
Sci. Technol. Arts Res. J., April-June 2014, 3(2): 93-102

$\mathrm{L}^{-1}$ ) of different photocatalysts $\mathrm{ZnO}$, pristine PANI, and $\mathrm{PANI} / \mathrm{ZnO}$ nanocomposite under visible light irradiation. The results shows that, $\mathrm{ZnO}$ has negligible photocatalytic activity under visible light irradiation. This is because of the large band gap of $\mathrm{ZnO}(3.27 \mathrm{eV})$ that is available only with the UV radiation and cannot be provided by visible light radiation used here. Pristine PANI has photocatalytic activity under visible light irradiation for the degradation of $\mathrm{MeO}$ molecules. The degradation or decolorization efficiency of $\mathrm{MeO}$ solution under visible light irradiation using pristine $\mathrm{PANI}$ and $\mathrm{PANI} / \mathrm{ZnO}$ nanocomposite were $38 \%$ and $81.3 \%$ at 2 hours. This may be because in case of $\mathrm{PANI} / \mathrm{ZnO}$, there is efficient charge separation of electron and hole pairs in the excited states that prevents recombination of charge pairs for a longer time under visible radiation (Olad and Nosrati, 2011).

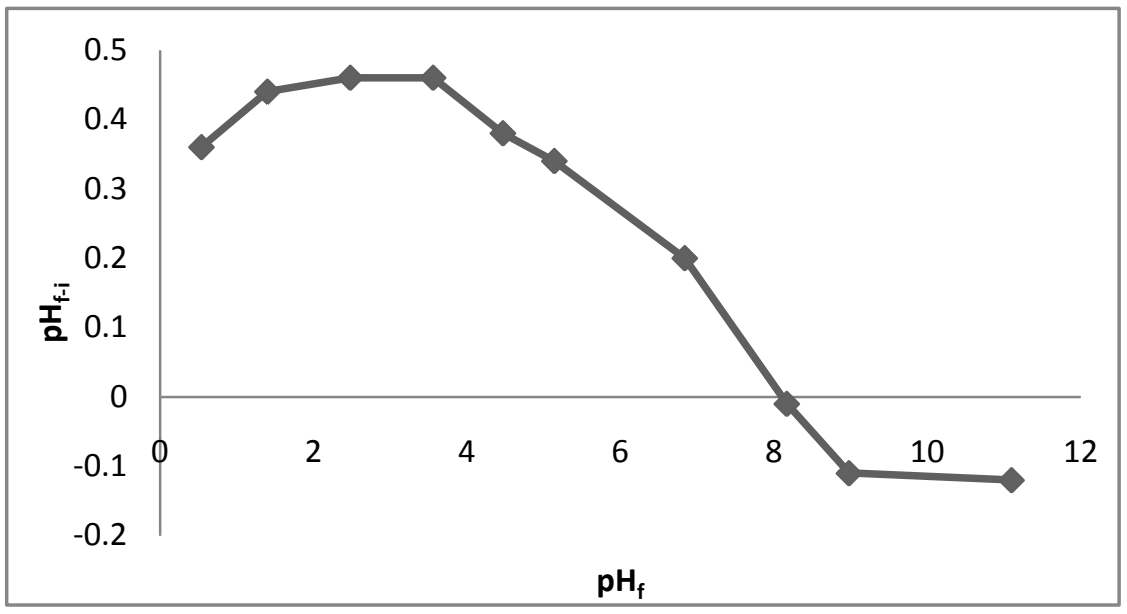

Figure 8: Plot of $\mathrm{pH}_{\mathrm{f}}$ versus $\mathrm{pH}_{\mathrm{f}-\mathrm{i}}$ of $\mathrm{PANI} / \mathrm{ZnO}$ nanocomposite.

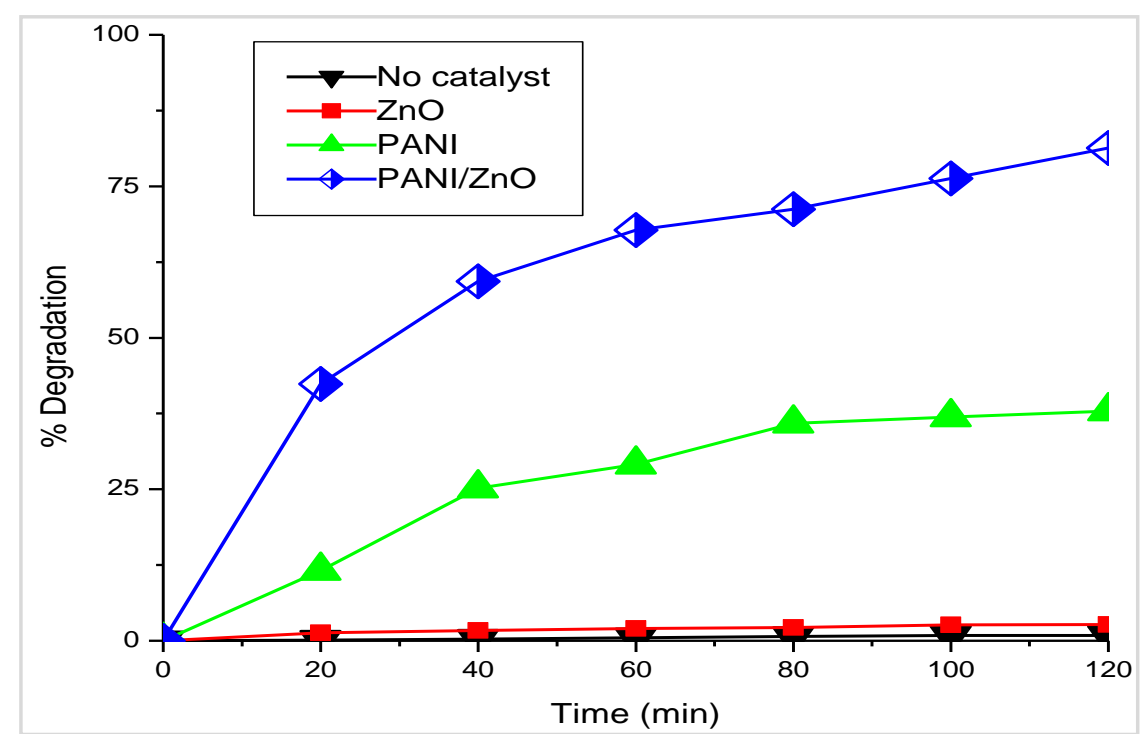

Figure 9: Plots of percentage degradation of $\mathrm{MeO}$ as function of time under Visible irradiation using $\mathrm{ZnO}, \mathrm{PANI}$ and $\mathrm{PANI} / \mathrm{ZnO}$ photocatalysts ( $\mathrm{MeO}=10 \mathrm{mgL}^{-1}, \mathrm{ZnO}, \mathrm{PANI}$ and $\mathrm{PANI} / \mathrm{ZnO}=1.50 \mathrm{gmL}^{-1}, \mathrm{pH}=6$ ).

\section{Effect of Irradiation Time}

The relationship between the percentage degradation of $\mathrm{MeO}$ dye by $\mathrm{PANI} / \mathrm{ZnO}$ photocatalyst and irradiation time is shown in Figure 9. It is clearly seen that the percentage degradation increases with increasing irradiation time and is $81.3 \%$ degradation at 120 minutes using PANI/ZnO photocatalyst.

\section{Effect of Photocatyst} on the Photocatalytic Degradation of MeO Dye

The amount of photocatalyst is one of the main parameters for the degradation of substrate from economical point of view. In order to avoid the use of excess photocatalyst, it is necessary to find out the optimum loading of photocatalyst for efficient removal of 
Melaku Wondwossen et al.,

dye (Sakthivel et al., 2003). Hence, a series of experiments were carried out to find the optimum amount of the photocatalyst (PANI/ZnO) by varying its amount from $0.50 \mathrm{gL}^{-1}$ to $2.50 \mathrm{gL}^{-1}$. The percent degradation of dye versus time of degradation by varying the photo catalyst weight is shown in figure 10 . To achieve highest photocatalytic reaction rate, the optimum amount of the photocatalyst is found to be $1.50 \mathrm{gL}^{-1}$. The observed dependence of reaction rate on the amount of photocatalyst can be explained in terms of the availability of active sites at the adsorbent surface and the level of
Sci. Technol. Arts Res. J., April-June 2014, 3(2): 93-102

light penetration in the reaction medium (Goncalve et al., 1999). Upon increasing the amount of photocatalyst up to $1.50 \mathrm{gL}^{-1}$ percent degradation increases due to the increase in the adsorbent total surface area and thus, the number of active sites, available for the photocatalytic reaction. However, excess photocatalyst, above optimal load, would induce more aggregation (particle-particle interactions) of photocatalyst making a significant fraction of the catalyst inaccessible either to the adsorbing dye or to the radiation (Wong and Chu, 2003).

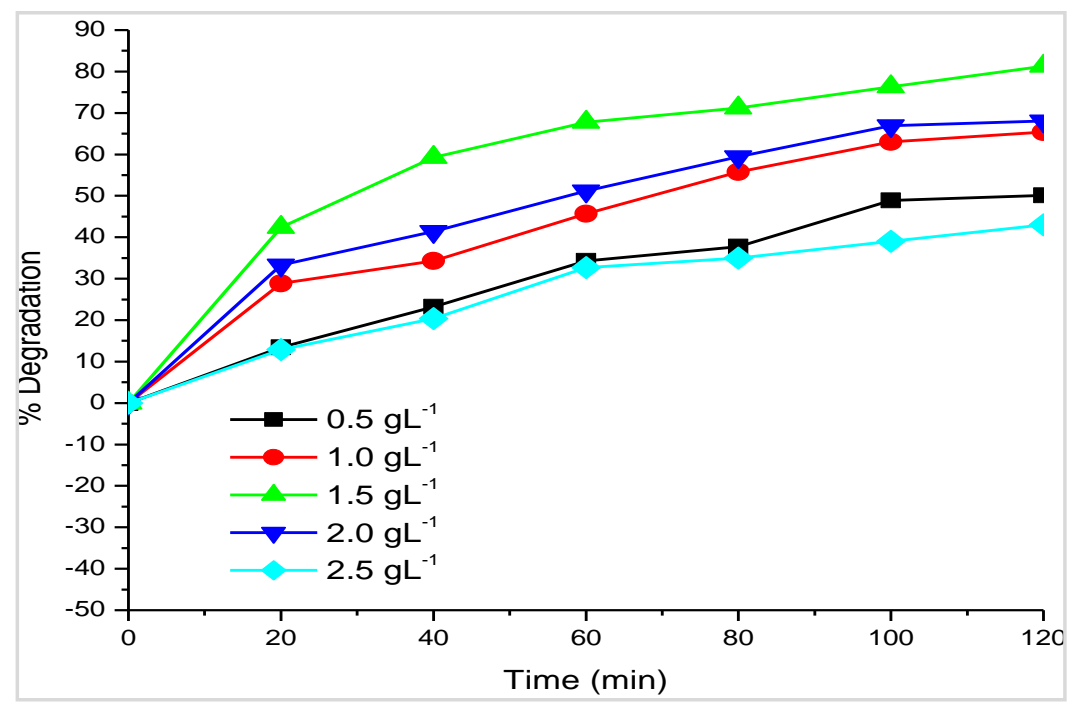

Figure 10: Plot of perecent degradation of $\mathrm{MeO}$ versus time by varying the amount of PANI/ZnO photocatalyst $(\mathrm{pH}=6$, $\left.\mathrm{MeO} 10 \mathrm{mgL}^{-1}, \lambda_{\max }=460 \mathrm{~nm}\right)$.

\section{Effect of pH}

The $\mathrm{pH}$ of solutions greatly affects the rate of reaction taking place on semiconductor surfaces due to its influences on surface-charge-properties of the photocatalysts. The effect of $\mathrm{pH}$ in the range of $\mathrm{pH} 3.0-$ 11.0 on the photo-catalytic degradation rate of $\mathrm{MeO}$ was investigated. Plot of photocatalytic degradation as a function of time is presented in figure 11. The strong effect of $\mathrm{pH}$ on the photodegradation efficiency of $\mathrm{MeO}$ solution was observed at $\mathrm{pH}$ of 6.0. Net charge on the photocatalyst surface is $\mathrm{pH}$ dependant. PANI/ZnO photocatalyst has point of zero charge $(\mathrm{pzc})$ at $\mathrm{pH}=8.17$. Below the pzc the photocatalyst has net charge positive and above the pzc the net charge on it is negative. Lower photocatalytic degradation at a lower $\mathrm{pH}$ (than pzc) is due to the less availability of $\mathrm{OH}^{-}$ions to form highly active $\mathrm{OH}^{\circ}$ radicals. At higher $\mathrm{pH}$ (than pzc) sorption of negatively charged $\mathrm{MeO}$ on the similarly charged photocatalyst decreases due to ion-ion repulsion and hence there is less photocatalytic degradation of $\mathrm{MeO}$ dye.

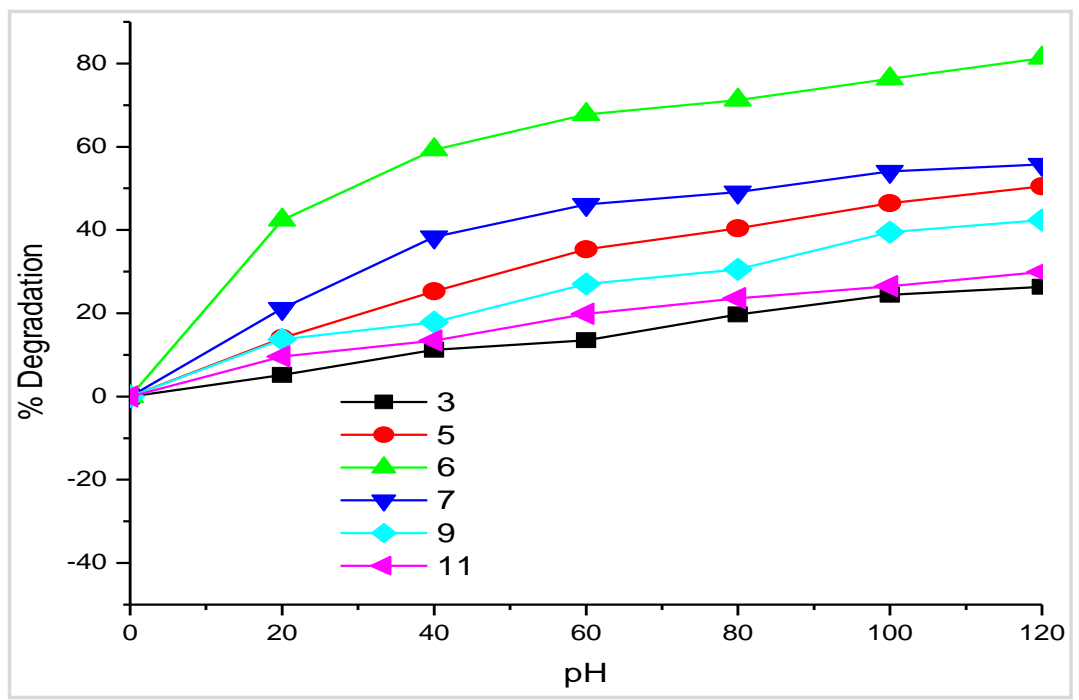

Figure 11: Plots of percent degradation of $\mathrm{MeO}$ as function of $\mathrm{pH}$ under visible irradiation using PANI/ZnO photocatalyst $\left(\mathrm{MeO}=10 \mathrm{mgL}^{-1}, \mathrm{PANI} / \mathrm{ZnO}=1.50 \mathrm{gL}^{-1}, \mathrm{pH}=6, \lambda_{\max }=460 \mathrm{~nm}\right)$. 
Melaku Wondwossen et al.,

Effect of Initial Concentration on the Photocatalytic Degradation of MeO Dye

The effect of the substrate initial concentration on the degradation of $\mathrm{MeO}$ dye was studied at different concentrations of dye varying from $10 \mathrm{mg} \mathrm{L}^{-1}$ to $50 \mathrm{mg} \mathrm{L}^{-1}$ keeping photocatalyst load $\left(1.50 \mathrm{gL}^{-1}\right)$. Figure 12 shows the percentage degradation of $\mathrm{MeO}$ dye in solutions with the same amount of PANI/ZnO photocatalyst $\left(1.50 \mathrm{~g} \mathrm{~L}^{-1}\right)$. The highest degradation was found to be maximum using $10 \mathrm{mg} \mathrm{L}^{-1}$ concentration of $\mathrm{MeO}$. As the dye concentration is increased and the catalyst amount is kept constant, fewer active sites are available per substrate (dye) to interact with. Thus, resulting in decreased rate of photocatalytic degradation (Davis et al., 1994, Poulios and Aetopoulou, 1999). Further, at higher dye initial concentration, the approach of the radiation photons to the catalyst surface is hindered and screened off, thereby,
Sci. Technol. Arts Res. J., April-June 2014, 3(2): 93-102

reducing the photocatalytic activity in the system (Epling and Lin, 2002; Zhu et al., 2000). Moreover, at the higher dye concentration, the number of collisions between dye molecules increases at the cost of required collisions between dye molecules and $\mathrm{OH}$ radical and therefore, the rate of reaction is retarded (Lodha et al., 2008).

\section{Kinetic Study of Dye Photo-catalytic Degradation}

The values of $\ln \left(\mathrm{C}_{0} / \mathrm{C}_{\mathrm{t}}\right)$ as a function of time for different concentration of $\mathrm{MeO}$ are shown in figure 13. The linear correlation of the plot of $\ln \left(\mathrm{C}_{0} / \mathrm{C}_{t}\right)$ as a function of time suggested that, photocatalytic degradation of $\mathrm{MeO}$ dye is a pseudo first-order reaction. The correlation constant for the fitted line was calculated to be $R^{2}=$ $0.996,0.989,0.993$ and 0.982 for $\mathrm{MeO}$ concentrations 10, 20,30 and $40 \mathrm{mgL}^{-1}$ respectively. The rate constants were calculated to be $0.014,0.01,0.004$ and 0.001 .

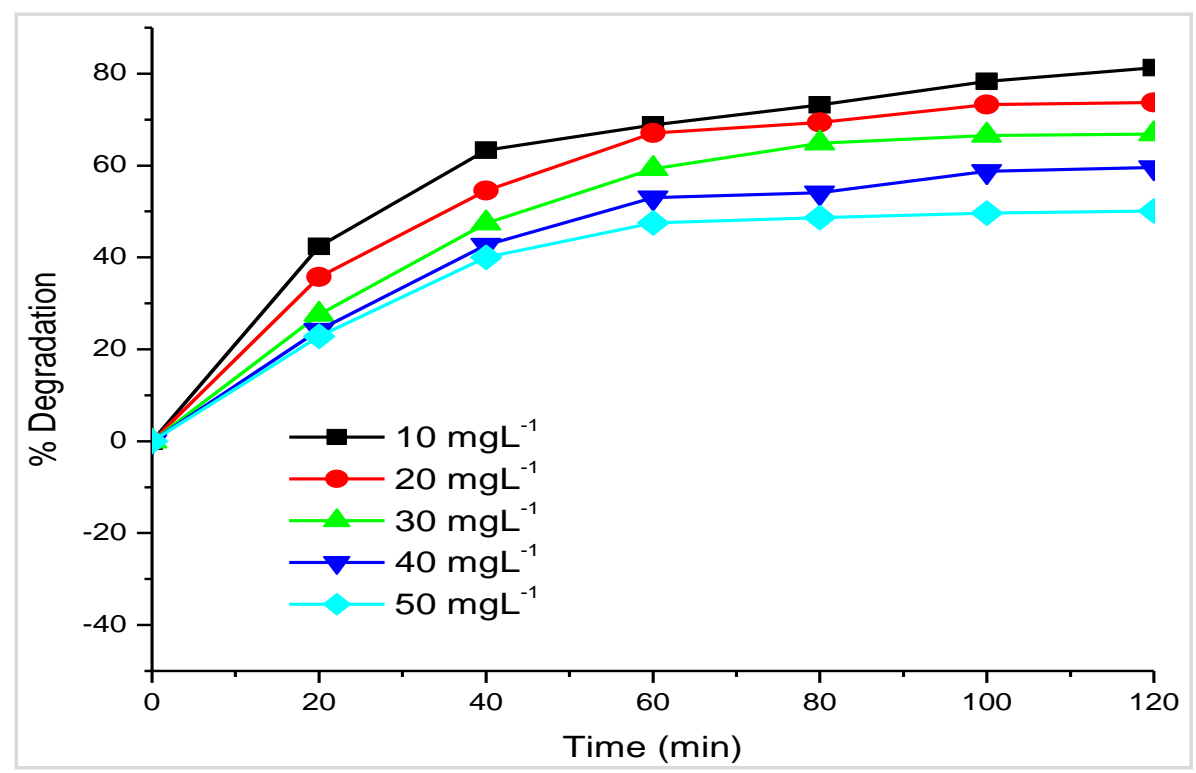

Figure 12: Plots of percentage degradation as function of time under visible light irradiation by keeping the $\mathrm{PANI} / \mathrm{ZnO}$ photocatalyst cconstant and varying the amount of $\mathrm{MeO}$ solution (PANI/ZnO $=1.50 \mathrm{gL}^{-1}, \mathrm{pH}=6, \lambda_{\max }=460 \mathrm{~nm}$ ).

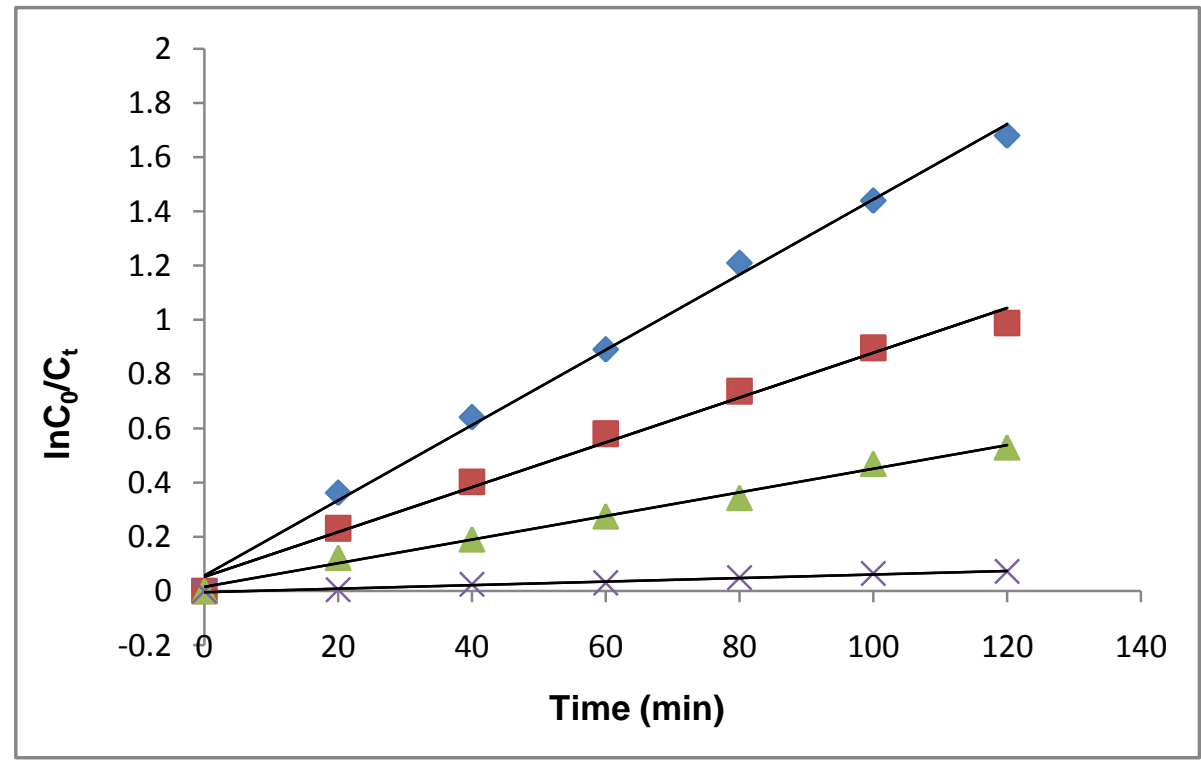

Figure 13: Plot of $\ln \left(\mathrm{C}_{0} / \mathrm{C}_{t}\right)$ as a function of time for photocatalyzed degradation of different concentration of MeO dye by $\mathrm{PANI} / \mathrm{ZnO}$ photocatalys $\left(\mathrm{PANI} / \mathrm{ZnO}=1.50 \mathrm{gL}^{-1}, \mathrm{pH}=6, \lambda_{\max }=460 \mathrm{~nm}\right.$ ). 


\section{CONCLUSIONS}

The PANI polymer and the PANI/ZnO nanocomposites have been successfully prepared via a facile chemical polymerization method. ZnO nanoparticles were successfully coated with PANI through 'in situ' chemical oxidative polymerization of aniline. The results of FTIR and UV-vis. confirm that there is a strong interaction between PANI and $\mathrm{ZnO}$ nanoparticles.

The superior photocatalytic effect of the PANI/ZnO nanocomposite is attributed to the synergistic effect of $\mathrm{PANI}$ and $\mathrm{ZnO}$ which promotes migration efficiency of the photogenerated carriers on the PANI/ZnO interface. The effects of operational parameters such as: amount of photocatalyst, $\mathrm{pH}$ of $\mathrm{MeO}$ solutions, and dye initial concentrations on the photocatalytic degradation rate of $\mathrm{MeO}$ solutions have been investigated. The photodegradation rate initially increases with the increase of catalyst amount up to optimum of PANI/ZnO photocatalyst $\left(1.50 \mathrm{gL}^{-1}\right)$, above this load the photodegradation rate of $\mathrm{MeO}$ solution decreases. The photocatalytic capacity of $\mathrm{PANI} / \mathrm{ZnO}$ nanocomposite towards degradation of methyl orange solutions also depends on the $\mathrm{pH}$ of $\mathrm{MeO}$ solutions, and there exists optimum $\mathrm{pH}$ (6.0) for maximum degradation of $\mathrm{MeO}$ dye. Photocatalytic degradation using polymer-sensitized $\mathrm{ZnO}$ composites presents a promising method for addressing environmental pollution. Thus, the PANI/ZnO nanocomposites are efficient photocatalytic materials for degrading contaminated colored wastewater for reuse in textile industries under mild conditions.

\section{ACKNOWLEDGEMENT}

I am deeply indebted to my advisors Prof. O. P. Yadav and Dr. Tesfahun Kebede for their invaluable and stimulating interest and unreserved support, most generously given during the course of my study. I pay respect and express indebtedness to them because of their guidance, consistent supervision as well as suggestions at every phase of this thesis work that made it possible to materialize.

\section{REFERENCES}

Ameen, S., Akhtar M.S., Kim Y.S., Yang O. and Shin H. (2011). An effective nanocomposite of polyaniline and $\mathrm{ZnO}$ : preparation, characterizations, and its photocatalytic activity. Colloid and Polymer Science 289: 415-421.

Bessekhouad, Y., Robert D. and Weber J.V. (2004). $\mathrm{Bi}_{2} \mathrm{~S}_{3} / \mathrm{TiO}_{2}$ and $\mathrm{CdS} / \mathrm{TiO}_{2}$ heterojunctions as an available configuration for photo catalytic degradation of organic pollutant. Journal of Photochemistry and Photobiology A: Chemistry 163: 569-580.

Chen, F. and Jie W. (2007). Growth and photoluminescence properties of CdS solid solution semiconductor. Crystal Research \& Technology 42: 1082- 1086.

Chen, F., Zhigang, X. Li, Zhang J. and Zhao J. (2005). Visible light detoxification by 2, 9, 16, 23-tetracarboxyl phthalocyanine copper modified amorphous titania. Chemical Physics Letters 415: 85- 88.

Dai, K., Chen H., Peng T., Ke D., Yi K. (2007). Photo catalytic degradation of methyl orange in aqueous suspension of meso porous Titania Nano particles. Chemosphere 69: 1361-1367.
Davis, R.J., Gainer J.L., Neal G.O. and Wu I.W. (1994). Photocatalytic Decolorization of Wastewater Dyes. Water Environment Research 66: 50-53.

Doong, R., Chen C., Mathreepala R.A., and Chang S. (2001). The influence of $\mathrm{pH}$ and cadium sulfide on the photo catalytic degradation of 2-chloro phenol in titanium dioxide suspensions. Journal of Veterinary Research 35: 2873-2880.

El-Kemary, M., El-Shamy H. and El-Mehasseb I. (2010). Photocatalytic degradation of ciprofloxacin drug in water using $\mathrm{ZnO}$ nanoparticles. Journal of Luminescence 130:2327-2331.

Epling, G.A. and Lin C. (2002). Photoassisted bleaching of dyes utilizing $\mathrm{TiO}_{2}$ and visible light. Chemosphere 46: 561- 570 .

Feng, W., Sun E., Fujii A., Wu H., Nihara K., Yoshino K. (2000). Synthesis and Characterization of Photoconducting Polyaniline-TiO2 Nanocomposite. Bulletin of the Chemical Society of Japan 73: 2627-2633.

Georgieva J, Armyanov S. and Valova E. (2007). Enhanced photocatalytic activity of electrosynthesised tungsten trioxidetitanium dioxide bi-layer coatings under ultraviolet and visible light illumination. Electrochemistry Communications 9: 365-370.

Goncalves, M.S.T., Oliveira-Campos A.M.F., Pinto E.M.M.S., Plasencia P.M.S. and Queiroz M.J.R.P. (1999). Photochemical Treatment of Solutions of Azo Dyes Containing $\mathrm{TiO}_{2}$. Chemosphere 39:781-786.

Gustafsson, G., Cao Y., Treacy G.M., Klavetter F., Colaneri N. and Heeger A. (1992). Flexible light emittind diods made from soluble conducting polymers. Nature 357: 477-479.

$\mathrm{He}, \quad$ Y. (2004). Preparation of polyaniline/nano-ZnO composites via a novel. Pickering emulsion route. Powder Technology 147: 59.

He, Y. (2005). ZnO composite fibers. Applied Surface Science 249: 1.

Hilal, H.S., majiad L.Z., Zaatar N. and El-Hamouz A. (2007). Dye-effect in $\mathrm{TiO}_{2}$ catalyzed contaminant photo degradation: Sensitization vss.Charge transfer form alism. Solid State Sciences 9: 9-15.

Kansal, S.K., Singh, M. and Sud, D. (2007). Studies on photo- degradation of two commercial dyes in aqueous phase using different photo catalysts. Journal of Hazardous Materials 141: 58 1-590.

Karim, M.R., Lee C.J., Park Y.T. and Lee M.S. (2006). Synthesis and characterization of conducting polythiophene/carbon nanotubes composites. Journal of Polymer Chemistry 14: 5283-5290.

Kathirvelu, S., D'Souza L.and Dhurai B. (2009). UV protection finishing of textiles using $\mathrm{ZnO}$ nanoparticles. Indian Journal of Fibre and Textile Research 34: 267-273.

Khanna, P.K., Lonker S., Subbarao V.S. and Jun K.W. (2004). Polyaniline/CdS nanocomposite from organometallic cadmium precursor. Materials Chemistry and Physics 87: 49-52.

Kim, S., Kim E., Kim S. and Kim W. (2005). Surface modification of silica nanoparticles by UV-induced graft polymerization of methyl methacrylate. Journal of Colloid and Interface Science 292(1): 93-98. 
Melaku Wondwossen et al.,

Lodha S., Vaya D., Ameta R. and Punjabi P. (2008). Photocatalytic degradation of Phenol Red using complexes of some transition metals and hydrogen peroxide. Journal of the Serbian Chemical Society 73: 631- 639.

Mbhele, Z.M., Sakmane M.G., van Sittert C.G.C.E., Nedeljkovic J.M., Djokovic V. and Luyt A.S. (2003). Fabrication and Characterization of Silver-Polyvinyl Alcohol Nanocomposites. Chemistry of Materials 15: 5019-5024.

Min, S., Wang F. and Han Y. (2007). An investigation on synthesis and photocatalytic activity of polyaniline sensitized nanocrystalline TiO2 composites. Journal of Materials Science 42: 9966-9972.

Neppolian, B., Choi H.C., Sakthivel S., Arabindoo B., and Murugesan V. (2002). Solar /UV-induced photo catalytic degradation of three commercial textile dyes. Journal of Hazardous Materials 89: 303 - 317.

Niu, Z., Yang Z., Hu Z., Lu Y., Han C.C. (2003). PolyanilineSilica Composite Conductive Capsules and Hollow Spheres. Advanced Functional Materials 13: 949-954.

Olad, A. and Nosrati R. (2011). Preparation, characterization, and photocatalytic activity of polyaniline/ZnO nanocomposite. Research on Chemical Intermediates 38(2): 326-336.

Parida, K.M., Dash S.S. and Das D.P. (2006). Physicochemical characterization and hotocatalytic activity of zinc oxide prepared by various methods. Journal of Colloid and Interface Science 298: 787-793.

Pouget, J.P., Hsu C.H., MacDiarmid A.G. and Epstein A.J. (1995). Structural investigation of metallic PAN-CSA and some of its derivatives. Synthetic Metals 69: 119-120.

Poulios, I. and Aetopoulou I. (1999). Photocatalytic Decomposition of Commercial Azo Dye Reactive Orange. Environmental Technology 20: 479.

Rao, V.S., Rao K.S., Rao M.N. and Bora1 U. S. (2011). Studies on the surface characterisation of newly prepared activated kaza's carbons. Asian Journal Of Biochemical and Pharmaceutical Research 2(1): 567-84.

Rashed, M.N. and El-Amin A.A. (2007). Photocatalytic degradation of methyl orange in aqueous $\mathrm{TiO}_{2}$ under different solar irradiation sources. International Journal of Physical Sciences 2(3): 073-081.
Sci. Technol. Arts Res. J., April-June 2014, 3(2): 93-102

Sakthivela, S.B., Neppolianb M.V., Shankarb B., Arabindoob M., Palanichamyb V. and Murugesanb V. (2003). Solar photocatalytic degradation of azo dye: comparison of photocatalytic efficiency of $\mathrm{ZnO}$ and $\mathrm{TiO}_{2}$, Solar Energy Materials and Solar Cells 77: 65-82.

Sedenkova I., Trchova M. and Stejskal J. (2008). The thermal degradation of polyanilinefilms prepared in solutions and weak acids and in water-FTIR and Raman spectroscopic studies. Polymer Degradation and Stability 93: 2147-2157.

Shaheen, S.E., Brabec C.J., Padinger F., Fromherz T., Hummelen J.C. and Sarıçiftçi N.S. (2001). $2.5 \%$ Efficient Organic Plastic Solar Cells. Applied Physics Letters 78: 841-843.

Sharma, B.K., Gupta A.K., Khare N., Dhawan S.K. and Gupta H.C. (2009). Synthesis and characterization of polyaniline-ZnO composite and its dielectric behavior. Synthetic Metals 159: 391-395.

Silva, R.F. and Zaniquelli M.E.D. (2002). Morphology of nanometric size particulate aluminium-doped zinc oxide films. Colloids and SurfacesA 551: 198.

Somani, P.R., marimuthu R., Mulik U.P., Sainkar S.R., Amelnerkar D.P. (1999). High piezoresistivity and its origin in conducting polyaniline/ $\mathrm{TiO}_{2}$ composites. Synthetic Metals 106: 45-52.

Wang, X., Li Y., Zhao Y., Liu J., Saide T. and Feng W. (2010). Synthesis of PANI nanostructures with various morphologies from fibers to micromats to disks doped with salicylic acid. Synthetic Metals 160: 2008-2014.

Wong, C.C. and Chu W. (2003). The direct photolysis and photocatalytic degradation of alachlor at different $\mathrm{TiO} 2$ and UV sources. Chemosphere 50: 981-987.

Xu, J.F., Lin J.Y. , Tang S.H. and Duy W. (1998). Preparation of $\mathrm{ZnS}$ nanoparticles by ultrasonic radiation method. Applied Physics A, 66(6): 639-641.

Xu, Z.X.,. Roy V.A.L, Stallinga P., Muccini M., Toffanin S., Xiang H.F. and Che C.M. 2007. Nanocomposite field effect transistors based on zinc oxide/polymer blends Applied Physics Letters 90: 223509/1-223509/3.

Zhu, C., Wang L., Kong L., Yang X., Zheng S., Chen F., Maizhi F. and Zong H. (2000). Photocatalytic degradation of azo dyes by supported $\mathrm{TiO}_{2}+\mathrm{UV}$ in aqueous solution. Chemosphere 41: 303-309. 